\title{
Piketty, Thomas (2014): Capital in the Twenty-First Century. Cambridge: The Belknap Press of Harvard University Press, 685 pp. ISBN: 978-0-674-43000-6.
}

\author{
"Negarse a tratar con números \\ raramente sirve a los intereses \\ de los menos pudientes"
}

Thomas Piketty, profesor de la Escuela de Economía de París, ha publicado un extenso y documentado análisis sobre la distribución de la riqueza en el sistema capitalista. La edición francesa original fue publicada en 2013, la inglesa utilizada en la presente reseña en 2014 y con posterioridad apareció la castellana en 2015. El libro ha sido ampliamente comentado y reseñado por algunos de los más importantes economistas y científicos sociales ${ }^{1}$. Incluso Bill Gates, el hombre "más rico del mundo", hizo una pequeña anotación crítica en su Blog². Esto no habla de las bondades ni de los problemas empíricos y teóricos del libro, pero si lo hace de su éxito. Lo cual no deja de resultar extraño, pues Piketty ha conseguido que un libro de economía de cerca de 700 páginas con una fuerte fundamentación matemática y analítica se convierta en un best-sel/er $r^{3}$. Parte de la respuesta a este hecho curioso puede encontrarse en su temática, pues la desigualdad económica y social es un fenómeno cada vez más presente en el debate público. Muestra de ello es la proliferación de artículos y libros

\footnotetext{
1 Sin pretensiones de exhaustividad, se incluyen algunas reseñas sobre el libro: Duque, I. (2015): "Piketty, Thomas (2013): Le capital au XXle siècle, Seuil, Paris. Un análisis sobre el capitalismo patrimonial globalizado y sus encrucijadas", Empiria. Revista de metodología de las ciencias sociales, 30: 183-199; Lobato, M. (2014): "Reseña de "El Capital en el Siglo XXI", de Thomas Piketty", perifèria, 19 (2): 144-156; Milanovic, B. (2013): "The return of "patrimonial capitalism": review of Thomas Piketty's Capital in the 21st Century", MPRA Paper, n. 52384, disponible en web: http://mpra.ub.uni-muenchen.de/52384/.

${ }^{2}$ Gates, B. (2014): "Why Inequality Matters", disponible en web: http://www.gatesnotes.com/Books/WhyInequality-Matters-Capital-in-21st-Century-Review.

Piketty contó en una conferencia, como anécdota, que Bill Gates le dijo: "Me encanta tu libro, pero no quiero pagar más impuestos".

${ }^{3}$ El libro, sin embargo, ha sido más un éxito en Estados Unidos que en la propia Francia. Allí El capital en el siglo XXI tuvo, en principio, unas ventas mucho más
} modestas. sobre el tema, dentro de los cuales el de Piketty es uno de los más exitosos.

El libro es el resultado de 15 años de trabajo y viene precedido por una abundante producción en forma de artículos académicos e incluso de algún libro sobre la misma temática ${ }^{4}$. Piketty no es un ensayista al uso, sino un profesor universitario ampliamente reconocido por la comunidad académica. Sin embargo, su dedicación a la universidad y ese reconocimiento no impide que Piketty adopte un punto de vista multidiciplinar, de un lado, y que use un tono divulgativo alejado de la escolástica académica. Así, se aleja de los planteamientos mainstream de la economía, es decir, intenta eludir una economía reducida a modelos econométricos de escaso recorrido. Aboga por incluir la economía dentro de las ciencias sociales y la obra tiene, sin duda, una buena parte de economía, pero también de historia, sociología y política. En sus propias palabras: "Veo la economía como una subdisciplina de las ciencias sociales, junto a la historia, la sociología, la antropología y las ciencias políticas" (p. 573). En todo caso, en el libro las matemáticas no ahogan el entendimiento de la economía, al contrario, lo esclarecen. Una de las cosas más interesantes es el intento de Piketty de mostrar en todo momento que los conceptos utilizados en economía están basados en una serie de presupuestos que han de ser contextualizados. Esto atenta contra la idea tan extendida de la economía como "ciencia exacta" y la acerca al resto de ciencias sociales.

En este sentido, una de las ideas básicas del libro es que la economía no es un "mecanismo" basado en "equilibrios naturales", sino que es fruto de decisiones y acciones humanas, en las cuales la política -entre otros factores-, tiene un peso fundamental. En esto, salvando las distancias, recuerda el trabajo de Max Weber ${ }^{5}$, para el cual vista de un modo histórico la economía de mercado es un modelo económico específico entre otros, una "forma" de la economía no el único tipo de economía "natural".

La primera y segunda parte del libro describen los principales conceptos utilizados en la obra y prestan especial atención a dos fenómenos: la estructura del capital acumulado en las sociedades más ricas utilizando la ratio capital/renta y el fenómeno del crecimiento económico y la acumulación de capital.

\footnotetext{
4 Piketty, T. (2015 [2008]): La economía de las desigualdades. Cómo implementar una redistribución justa y eficaz de la riqueza. Barcelona: Anagrama.

${ }^{5}$ Sobre todo en su (2001 [1923]): Historia económica general. México: FCE.
} 
Sostiene que las sociedades sin crecimiento económico son sociedades donde la riqueza heredada pesa más en la renta disponible.

"Las sociedades dominadas en el pasado por el capital, con jerarquías ampliamente determinadas por la riqueza heredada (una categoría que incluye tanto las sociedades rurales tradicionales como los países del siglo XIX en Europa), pueden surgir y subsistir sólo en regímenes de bajo crecimiento" (p. 84).

El libro plantea que según las proyecciones más habituales se producirá una reducción en el crecimiento poblacional durante este siglo. Lo mismo ocurrirá con las tasas de crecimiento económico, que no excederán del $1,5 \%$ de media -la tasa histórica habitual, por otra parte- y se alejará de crecimientos excepcionales del 3 y $4 \%$ anual. En definitiva, la ausencia de crecimiento poblacional y económico de tipo explosivo nos acercará a una situación similar a la del siglo XVIII y XIX, convirtiéndonos en sociedades dominadas por el capital heredado o sociedades de "capitalismo patrimonial".

Además, a partir de los años setenta del siglo pasado en los países más ricos se produjo un aumento del capital privado. Esto se debió a tres motivos: un bajo crecimiento, sobre todo demográfico, unido a un incremento del ahorro; la privatización y transferencia de capital público a manos privadas; y una recuperación del precio de los activos financieros e inmobiliarios, bajos durante la mitad del siglo XX. A lo largo del siglo XXI, sostiene, se acentuará esta tendencia, que "obviamente, es solo una posibilidad entre otras" (p. 196), aunque plausible.

Mantiene que existen dos tipos de rentas: las que provienen del trabajo y las que lo hacen del capital. La suma de ambas, en una nación concreta, sería la renta nacional. Le interesa especialmente medir el porcentaje del capital en la renta nacional y poder así comprobar si este ha aumentado o disminuido históricamente respecto al porcentaje que corresponde a las rentas del trabajo. Según los datos recopilados por el autor, desde 1970 se produjo un claro aumento de la participación del capital frente al trabajo en la renta nacional. Así,

"el crecimiento moderno, que está basado en el crecimiento de la productividad y la difusión del conocimiento, ha hecho posible evitar el apocalipsis predicho por Marx y equilibrar el proceso de acumulación capitalista. Pero no ha alterado las estructuras profundas del capital -o en todo caso no ha reducido de verdad la importancia macroeconómica del capital respecto al trabajo-" (p. 234).

El capital, por tanto, sigue siendo una fuerte importante de la generación de ingresos para una parte de la sociedad. Esto, según Piketty conduce a un incremento de la desigualdad, que es revisado en la tercera parte del libro. La causa estaría en, por un lado, el aumento de las desigualdades de las rentas provenientes del trabajo en algunos contextos geográficos (sobre todo en Estados Unidos y Reino Unido con la aparición de "super-gerentes" pagados muy por encima de la media de esos países), de un lado; $y$, de otro, por la cada vez mayor importancia del capital heredado en la generación de ingresos, sobre todo en las capas superiores de la sociedad. El aumento de la desigualdad es, sin duda, una de las principales ideas-fuerza del libro.

"Desde los años 70, la desigualdad de ingresos se ha incrementado significativamente en los países ricos, especialmente en los Estados Unidos, donde la concentración de rentas en la primera década del siglo XXI ha recuperado -incluso, excede ligeramente- el nivel alcanzado en la segunda década de siglo pasado" (p. 15).

El aumento de la desigualdad no es, afirma, un proceso natural, sino consecuencia de cambios políticos, sobre todo en las políticas fiscales y financieras. Trata de rebatir la famosa tesis de Simon Kuznets, según la cual con el inicio de la industrialización se disparó la desigualdad para con el paso del tiempo irse amortiguando y finalmente reduciéndose. La curva de la desigualdad tendría la forma de una "U" invertida. Según Piketty, los datos no avalan esta teoría, al menos durante el siglo XX y principios del XXI. La curva tendría más bien la forma de una " $U$ ", en este caso sin invertir, lo que indicaría altos niveles de desigualdad a finales del siglo XIX y principios del $\mathrm{XX}$, una reducción de la desigualdad a mediados del siglo $\mathrm{XX}$, y desde los años 70 del pasado siglo un nuevo aumento de la misma.

Recalca durante la obra que los factores más importantes, visto desde el largo plazo, en la reducción de la desigualdad durante el siglo XX fueron las dos Guerras Mundiales. "En el siglo XX fue la guerra, y no una racionalidad económica $\mathrm{O}$ una democracia armoniosa, lo que borró el pasado y permitió a la sociedad comenzar de nuevo" (p. 275). De hecho, sostiene que una vez superada la reconstrucción posterior a la Segunda Guerra Mundial, las desigualdades crecieron en todos los países desarrollados y que las previsiones para el siglo XXI es que lo sigan haciendo hasta situarse en un plano similar al del siglo XIX.

En la cuarta parte del libro entra dentro de la más estricta política económica y formula una serie de propuestas para intentar reducir la desigualdad económica, vista como un elemento que socaba la democracia. Para ello, aboga por una política fiscal basada en un impuesto progresivo sobre las rentas del trabajo, incluso confiscatorio para las rentas más altas, y un impuesto sobre el capital de nivel global que afectaría a todos los tipos de capital. Incluso cree que la mejor solución para la crisis de deuda de las 
economías avanzadas sería la imposición durante un número limitado de años de un impuesto especial sobre el capital, puesto que los demás mecanismos para reducir la deuda: austeridad o inflación, se muestran menos eficaces.

Para concluir este breve repaso por las ideas del economista francés, debe señalarse que rechaza la idea de que el comercio internacional en sí mismo enriquezca a ambas partes por igual y reduzca la desigualdad. El principal mecanismo redistribuidor de la riqueza no sería el comercio, sino la difusión del conocimiento.

"Para resumir, la experiencia histórica sugiere que el principal mecanismo para la convergencia tanto a nivel internacional como local es la difusión de conocimiento. En otras palabras, los pobres alcanzan a los ricos en la medida en que consiguen el mismo nivel de saber-hacer tecnológico, de habilidades y de educación, no al convertirse en propiedad de los ricos" (p. 71).

Sin embargo, reconoce que el libre comercio y la apertura internacional favorecen la difusión del conocimiento, por sí mismo no es suficiente, pues la adquisición de nuevas técnicas y habilidades requiere del concurso del poder político.

En el debate suscitado con posterioridad, diversos autores han rebatido los planteamientos del Capitalismo en el siglo XXI. Las principales críticas pueden ser agrupadas en cuatro frentes: ideológico, empírico, teórico y político. En primer lugar, la crítica conservadora ha señalado el posicionamiento ideológico de Piketty, al calificar el libro de "marxismo light". Se le acusa de utilizar las estadísticas como un simple mecanismo para adornar una postura previa basada en prejuicios ideológicos. En segundo lugar, se generó cierta polémica, iniciada por el Financial Times, sobre la bondad de los datos utilizados como base para el análisis. Estas acusaciones fueron contestadas por el propio Piketty. En todo caso, los datos han sido puestos a disposición de cualquier investigador por el autor en la red, lo cual indica que no tenía intención de ocultarlos en modo alguno y que, al contrario, buscaba la confrontación crítica.

En tercer lugar, también se han realizado algunas críticas respecto a la perspectiva teórica del libro. Desde posiciones más liberales se le ha reprochado el hecho de centrarse en las desigualdades sin tener en cuenta el avance general de las poblaciones, es decir, no contemplar la reducción global de la pobreza que sería compatible con un aumento de la desigualdad. A saber, somos más desiguales, pero los pobres lo son menos. Como afirma Martin Wolf: "Incluso los pobres disfrutan de bienes y servicios inaccesibles para los más ricos hace unas décadas" ${ }^{\prime 6}$. Desde la izquierda, se

${ }^{6}$ Wolf, M. (2014): "Capital in the Twenty-First Century, by Thomas Piketty", Financial Times, April 15, le ha criticado por describir el aumento de la desigualdad sin haber profundizado en la explicación de su existencia. David Harvey, por ejemplo, le reprocha basarse en presupuestos de la economía neoclásica y no haber leído a Marx ${ }^{7}$. También se ha discutido el concepto de capital como un conjunto de "cosas", heredado de la economía neoclásica, frente al concepto de capital como un proceso de creación propio de la economía marxista ${ }^{8}$. De hecho, define el capital como "la suma total de los bienes no humanos que pueden ser poseídos o intercambiados en algún mercado" (p. 46). O por fundir deliberadamente los conceptos de capital y riqueza9: "Uso las palabras capital y riqueza de un modo intercambiable, como si fuesen perfectos sinónimos" (p. 47).

Por último, también se han criticado las soluciones que Piketty sugiere para revertir la situación de creciente desigualdad, a saber, los impuestos progresivos y sobre sucesiones en la esfera nacional y un impuesto global sobre la riqueza. Para la derecha, esta es una propuesta irrealizable que lejos de disminuir la desigualdad, la aumentará al ralentizar el crecimiento económico. Para algunos sectores de la izquierda también es una propuesta inocente y "utópica", desligada de la verdadera fuente igualitaria: la inversión pública y el refuerzo del Estado de Bienestar.

Estas críticas lejos de restar valor al libro, se lo añaden. Es una obra con una tesis fuerte apoyada con un aparato analítico y estadístico poderoso que, sin duda, fue escrita precisamente para generar debate. Sin embargo, hay algo que destaca en el planteamiento de todo el libro $-y$ que no puede decirse de muchos de sus críticos-: Piketty siempre presenta sus argumentos como hipótesis y declara su

disponible en web:

http://www.ft.com/intl/cms/s/2/0c6e9302-c3e2-11e3a8e0-00144feabdc0.html\#axzz2yz1aCVku.

7 Harvey, D. (2014): "Afterthoughts on Piketty's Capital", disponible en web: http://davidharvey.org/2014/afterthoughts-pikettyscapital/

8 Galbraith, J. K. (2014): "Kapital for the Twenty-First Century?", disponible en web: https://www.dissentmagazine.org/article/kapital-forthe-twenty-first-century

${ }^{9}$ Brooks, M. (2014): "Review: thomas Piketty -Capital in the Twenty-First Century", The Project. A Socialist Journal, disponible en web: http://www.socialistproject.org/debate/review-thomaspiketty-capital-in-the-twenty-first-century/; Roberts, M. (2014): "Unpicking Piketty", weeklyworker, disponible en web: http://weeklyworker.co.uk/worker/1013/unpickingpiketty/; o Varoufakis, Y. (2014): "Egalitarianism's latest foe: a critical review or Thomas Piketty's Capital in the Twenty-First Century", real-world economics review, 69: 18-35. 
validez solamente en relación a los datos disponibles en el momento actual de la investigación.

También existe un punto destacado en el debate que va más allá de los números y la teoría económica: la asunción de que una gran desigualdad socava la democracia. Este planteamiento de Piketty es de enorme interés, pues supone una intersección entre la teoría política y la económica, uno de esas "tierras de nadie" en las cuales descansan los problemas reales de las personas. ¿Pueden las democracias occidentales soportar altos niveles de desigualdad sin desestabilizarse? ¿Puede esta, como planteaba Karl Polanyi, llevar a la aparición de profundas fisuras en la estructura social y crear "monstruos" totalitarios? Tal vez lo más interesante de libro del profesor Piketty comience donde él lo deja.

Antonio Martín-Cabello Universidad Rey Juan Carlos, España antonio.martin@urjc.es

Recibida: 28-08-2015

Aceptada: 12-10-2015

(c) (1) (3) 